This article has been accepted for publication in Cognition \& Emotion, published by Taylor \& Francis (https://doi.org/10.1080/02699931.2021.1964940).

\title{
Trolleys, Triage and Covid-19: The Role of Psychological Realism in Sacrificial Dilemmas
}

\author{
Markus Kneer ${ }^{1} \&$ Ivar R. Hannikainen ${ }^{2} *$ \\ ${ }^{1}$ Department of Philosophy, University of Zurich, Switzerland \\ ${ }^{2}$ Department of Philosophy I, University of Granada, Spain
}

Author Note

The research was supported by a Swiss National Science Foundation grant

(PZ00P1_179912, PI Markus Kneer). Data and materials are available on the Open Science

Framework at: osf.io/dpsq9/?view_only=54a7c150e03d4d78819b2954cee3a240.

* Correspondence concerning this article should be addressed to Ivar Rodríguez Hannikainen,

Department of Philosophy I, Faculty of Psychology, Cartuja Campus, Universidad de Granada

(Spain), 18011. Contact: ivar@ugr.es

Word Count: 8737 


\begin{abstract}
At the height of the Covid-19 pandemic, frontline medical professionals at intensive care units around the world faced gruesome decisions about how to ration life-saving medical resources. These events provided a unique lens through which to understand how the public reasons about real-world dilemmas involving trade-offs between human lives. In three studies (total $N=2298$ ), we examined people's moral attitudes toward triage of acute coronavirus patients, and found elevated support for utilitarian triage policies. These utilitarian tendencies did not stem from period change in moral attitudes relative to pre-pandemic levels--but rather, from the heightened realism of triage dilemmas. Participants favored utilitarian resolutions of critical care dilemmas when compared to structurally analogous, non-medical dilemmas — and such support was rooted in prosocial dispositions, including empathy and impartial beneficence. Finally, despite abundant evidence of political polarization surrounding Covid-19, moral views about critical care triage differed modestly, if at all, between liberals and conservatives. Taken together, our findings highlight people's robust support for utilitarian measures in the face of a global public health threat, and illustrate how hypothetical scenarios in moral psychology (e.g. trolley cases) should strive for more experiential and psychological realism, otherwise their results might not generalize to real-world moral dilemmas.
\end{abstract}

Keywords: moral judgment; values; Covid-19; utilitarianism; politics. 


\section{Trolleys, Triage and Covid-19: The Role of Psychological Realism in Sacrificial Dilemmas}

Early on in the Covid-19 pandemic, case rates and deaths saw exponential growth. Their trajectory surpassed numerous governments' predictions, and quickly depleted medical resources at many intensive care units (ICUs) around the world. As a result, frontline medical professionals faced what some imagined would remain an outlandish philosophical thought experiment: the choice whether to sacrifice some patients in order to save a larger number of lives (Emanuel et al., 2020). The Covid-19 pandemic brought the infamous trolley problem (Foot, 1967) to life, and provided a unique opportunity for moral psychologists to explore how the public approaches such tragic dilemmas when contextualized in ecologically valid settings involving triage at the ICU. What should frontline doctors do when faced with the decision whether to sacrifice one patient to prioritize saving more lives? The purpose of our present work is to explore this exact question (see also Arora, Savulescu, Maslen, Selgelid \& Wilkinson. 2016; Wilkinson, Zohny, Kappes, Sinnott-Armstrong, \& Savulescu, 2020).

Below, we first distill past findings drawn from the literature on hypothetical sacrificial dilemmas, and echo previous concerns about limits to their ecological validity—which our studies then partly substantiate. Additionally, we review distinct models according to which various contextual elements (e.g., personal susceptibility, period change) could modulate the public's moral attitudes. Turning to our studies, we document pronounced utilitarian tendencies in triage contexts (Study 1), and test two distinct explanations for this effect in Studies 2 and 3: period change and psychological realism, respectively. In closing, we elaborate on the practical implications of these results for public health guidelines governing the allocation of critical care resources, and highlight their theoretical implications for traditional approaches to the study of moral cognition. 


\section{Sacrificial Dilemmas}

Research in moral psychology relies heavily on "sacrificial dilemmas" (Bartels \& Pizarro, 2011) in which impending harm to a larger group of people can be avoided by harming a smaller group instead. Among the most famous of these hypothetical scenarios are two versions of the trolley dilemma, in which a runaway trolley will kill five workmen unless something is done (Foot, 1967; Thomson, 1976, 1985). In the Bystander version, the trolley can be diverted onto another track by operating a lever, where it would run over a single worker instead. In the Footbridge version, the trolley can be stopped before it reaches the workmen by pushing a heavy man off a footbridge and into the trolley's path.

Contrary to utilitarian moral principles, people report conflicting intuitions about these cases: choosing to save the larger number of lives in Bystander but not in Footbridge. Hundreds of empirical studies have now employed sacrificial dilemmas (for a review, see Christensen \& Gomila, 2012) to characterize the psychological basis of this distinction (e.g., Bartels \& Pizarro, 2011; Conway \& Gawronski, 2013; Cushman et al., 2006; Greene et al., 2001, 2009; Patil, 2015) and examine its generalizability across cultures (Awad et al., 2020) and birth cohorts (Hannikainen et al., 2018). This large empirical literature has also inspired sophisticated theoretical developments, from Greene and colleagues' $(2001,2007)$ dual process theory, and Mikhail's $(2007,2009)$ universal moral grammar to the two-dimensional model of utilitarianism advanced by Kahane, Everett and colleagues (Kahane et al., 2015 2018).

Among the most recurring findings in this literature is the association between affective empathy and opposition to utilitarian sacrifice (Gleichgerrcht \& Young, 2013). For instance, deficits in empathy have been associated with stronger utilitarian tendencies (Patil \& Silani, 2014), which may help to explain why psychopathic individuals report more favorable attitudes 
toward utilitarian sacrifice than do psychotypical controls (Koenigs et al., 2012). This line of research has inspired skepticism about the relationship between sacrificial dilemmas and utilitarian thought in moral philosophy (but see Conway et al., 2018). Namely, utilitarian reactions to hypothetical dilemmas may not reflect a concern for the greater good (Kahane et al., 2015) but rather a reduced aversion to causing harm (Miller et al., 2014) that accompanies Dark Triad traits (i.e., Machiavellianism, narcissism, and psychopathy; see Bartels \& Pizarro, 2011; Patil, 2015).

Experimental studies employing immersive methods to elevate affective engagement have provided further nuance. If affective empathy primarily constrains utilitarian sacrifice, then inducing greater engagement ought to elicit stronger affective reactions and further dampen utilitarian tendencies. Yet, efforts to make sacrificial dilemmas more vivid and life-like--e.g., through the use of virtual reality (Patil et al., 2014; Francis et al., 2016), haptic feedback (Francis et al., 2017), or the anticipation of actual harm to mice (Bostyn et al., 2018)--have all revealed evidence to the contrary. Immersive research methods in fact strengthen people's utilitarian motivation, when compared to their responses to abstract narrations of those same dilemmas.

These results cannot readily be explained when associating affective empathy in the opposition to harmful acts. According to the two-dimensional model of utilitarianism, utilitarian tendencies manifest in the general population as two distinct — and even unrelated — attitudes: approval of instrumental harm and impartial beneficence. Reactions to sacrificial dilemmas are linked primarily to beliefs about the permissibility of instrumental harm (Kahane et al., 2015 2018), while being largely unrelated to impartial beneficence. Could enhancing the ecological validity of moral dilemmas elevate utilitarian tendencies by promoting specifically beneficent motivations to act? Our studies pursue this hypothesis, which (if supported) could help reconcile 
the well-known association between affective deficits and utilitarian sacrifice (in traditional, textbased dilemmas) with evidence that more immersive experimental paradigms have the opposite effect: i.e., of strengthening utilitarian motivation.

\section{External Validity}

In an influential paper, Bauman and colleagues (2014) raised concerns regarding the external validity of research on sacrificial dilemmas - that is, the extent to which the findings generalize to other, real-world situations (Campbell, 1957). Drawn from analytic philosophy, the dilemmas tend to be "set in fanciful, sometimes absurd, contexts, and these artificial settings may affect the way people approach the situation and decide what to do" (Bauman et al., 2014, p. 536). Among philosophers, such thought experiments are fruitfully employed to elicit intuitions within the philosophical community. However, since people are not acquainted with the discipline's conventions and methods (Converse, 1964; Tenbrunsel \& Messick, 1999), they may approach these dilemmas with a very different motivation.

The external validity of sacrificial dilemma stimuli may be compromised by three different factors (Aronson et al., 1998): First, they could fail to meaningfully engage the participant, for instance, if they are met with amusement (experimental realism). Second, they may be too dissimilar to the situations participants routinely encounter in their lives (mundane realism). Consequently, participants might question central premises (e.g., could the heavy man actually stop the trolley?), and be reluctant to accept the scenario (as seen, e.g., in Greene et al., 2009). Third, the scenarios might also lack psychological realism-partly as a consequence of low experimental and mundane realism: They may not elicit the same cognitive processes that take place in real-world circumstances. Unrealistic scenarios might, for instance, fail to produce characteristic reactions such as outrage toward transgressors or avoidance of those who manifest 
different moral values (for evidence that trolley dilemmas are wanting in this regard, see Baumann et al., 2012, Study 3).

Sacrificial dilemmas related to the Covid-19 pandemic - henceforth triage or critical care dilemmas - may overcome some of these limitations (Buckwalter \& Peterson, 2020; Wilkinson et al. 2020; Romero-Rivas et al., 2021; Reeskens et al. 2021; Francis \& McNabb, 2021; Antoniou et al., 2021). First, due to a shortage of supplies and staff, medical personnel at numerous intensive care units around the world — particularly during the first wave - faced actual sacrificial dilemmas. Second, the death toll due to coronavirus rose rapidly, and received continuous press coverage. Third, in addition to the health burden of the virus itself, the pandemic has also brought about changes in lifestyle, mental health, occupational status, and family life that have dramatically affected everyone. It stands to reason, then, that triage dilemmas have both experimental and mundane realism; they are real-life situations with which most participants are at least indirectly acquainted. Consequently, we suspected that their level of psychological realism would also be high. And indeed, transgressors of health and security measures tend to witness the full spectrum of reactions (e.g., outrage, contempt, disgust, see Rozin et al., 1999) known to accompany moral misbehavior. Disagreements over the correct political response to the pandemic as well as individual distancing measures have engendered heated debate, manifestations drawing large crowds, and destroyed many a relationship, as research on prejudice toward morally dissimilar others would predict (Skitka et al., 2005; Cole Wright et al., 2008). 


\section{Prevalence, Proximity and Period}

Susceptibility to severe coronavirus infection varies across time and locations (i.e., with fluctuation in contagion and case rates) and also across individuals (i.e., depending on health factors). This variation provided two distinct tests of the psychological realism hypothesis.

When we ran the first wave of studies, in mid-April 2020, the bulk of infections and deaths were limited to a handful of US states, including New York, Pennsylvania and Michigan. Most other states had extremely low infection rates, many vacant hospital beds, and barely any coronavirus-related deaths. Thus, in New York City, which was seeing hundreds of daily deaths and where hospitals were at maximum occupancy, a triage dilemma would plausibly have been much more realistic than in Wyoming, which at the time had a total of 296 confirmed cases, plenty of hospital bed availability, and only two coronavirus-related deaths (New York Times, 2020). We hypothesized that regional variation in Covid-19 prevalence could affect psychological realism, and therefore operationalized county-level case rates as a first realism proxy.

Another feature that may affect the realism of triage dilemmas is participants' individual susceptibility to Covid-19 hospitalization and death. An elderly, at-risk person concerned with their own risk of developing severe symptomatology, or an essential worker witnessing multiple coronavirus-related deaths every day as part of their profession might view triage dilemmas in a more realistic light than average. To evaluate this feature, which we labeled proximity, several items in our survey assessed the degree to which people were personally affected by the pandemic.

Thus, whereas prevalence constituted an objective measure of participants' exposure to Covid-19 (in virtue of their geographic location), proximity was a self-reported measure of 
participants' subjective affectedness (owing to factors such as occupational hazard, health status, and so on).

Finally, we also explored whether the pandemic induced a general change in people's utilitarian inclinations. To examine this question, we compared participants' judgments of traditional sacrificial dilemmas during the pandemic (in May 2020) to a dataset collected one yea prior. A potential period effect in responses, however, must be interpreted with caution. Given that, at the height of the pandemic, triage dilemmas received ample attention in mainstream media, and were at times discussed in conjunction with classic philosophical thought experiments (e.g., The Atlantic, 2020), a period effect could also indicate a perceived increase in realism and relevance of traditional dilemmas.

\section{Overview}

Our studies were conducted with approval from the Ethics Commission of the University of Zurich. We first report attitudes toward a series of critical care dilemmas across high and low prevalence states (Study 1). Then, in Studies 2 and 3, we pursue two potential explanations for the emergence of heightened utilitarian tendencies in response to triage dilemmas involving coronavirus patients: a period effect (Study 2) and a realism effect (Study 3). After reporting on the three studies, we turn to individual difference analyses which help to elucidate variation in response to triage versus traditional dilemmas.

Data and materials are available on the Open Science Framework at osf.io/dpsq9/?view_only=54a7c150e03d4d78819b2954cee3a240. We disclose all measures, manipulations, and exclusions in the studies. Participants were adults residing in the United

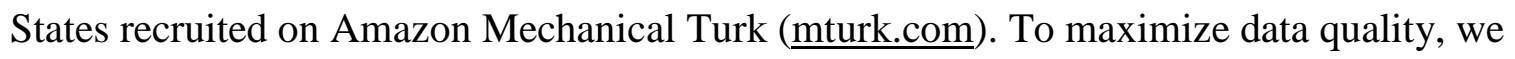
screened out participants who failed a two-part attention check at the start of the experiment. 
This attention check resulted in 453 exclusions in Study 1 (33\% exclusion rate), 149 exclusions in Study 2 (14\% exclusion rate), and 78 exclusions in Study 3 (14\% exclusion rate). The method by which we determined the sample size for each study is reported in the corresponding 'Power Analysis' subsections.

Frequentist and Bayesian analyses were conducted using $R$ version 3.6.2 and the car (Fox \& Weisberg, 2019) and BayesFactor (Morey \& Rouder, 2018) packages. Pairwise comparisons of simple and marginal effects were calculated with the emmeans (Lenth, 2019) package, applying Tukey correction for multiple comparisons (notated as $p_{\text {Tukey }}$ throughout the Results sections).

\section{Study 1}

In Study 1, we surveyed participants' attitudes toward critical care triage at the height of the Covid-19 pandemic. The core questions in Study 1 were: Do people typically favor or oppose utilitarian standards in ICU triage? Do such attitudes toward ICU triage depend upon the magnitude of the Covid-19 threat? To answer our second question, we evaluated the effects of geographic variation in the health burden of Covid-19 (as measured by daily, county-level updates of case and mortality rates) by sampling from high and low prevalence regions of the United States, and also the effects of subjective beliefs about the virus's severity.

\section{Methods}

\section{Materials}

For Study 1, we devised three different critical care dilemmas: Redirect, Withdraw, and Jeopardize. Each dilemma involves the sacrifice of a human life in order to save a larger number of lives. In Redirect, an oxygen tank is on its way to a hospital where a single coronavirus patient requires urgent treatment. The decision must be made whether to redirect the oxygen tank to a 
second ICU nearby where five, similarly critical, coronavirus patients recently checked in. Meanwhile, in Withdraw, an oxygen tank is already in use to treat a single coronavirus patient at a hospital ICU. This time, the decision must be made whether to disconnect the oxygen tank and drive it to a second ICU to save five coronavirus patients. Thus, the Redirect/Withdraw pair serves as a test of the so-called 'equivalence thesis': i.e., the notion that withholding and withdrawing treatment are equivalent from a moral point of view (Sulmasy \& Sugarman, 1994). Finally, in Jeopardize, a frail essential worker can be sent to pick up an oxygen tank and drive it to an ICU where five coronavirus patients have just checked in. However, in doing so, the essential worker would likely contract coronavirus and die.

In every scenario, we stipulated that - with near-certainty - the patients would survive if they received supplementary oxygen, and would die otherwise. We also stated that the patients could not be transported (due to their critical condition), that a decision had to be made imminently, and that there were no further alternatives (i.e., additional oxygen tanks, alternative treatments, etc.).

\section{Participants}

Between April $17^{\text {th }}$ and April $21^{\text {st }} 2020$, we recruited 906 crowdworkers (53\% women; age: $M=38.9, S D=13.0$, range $=18$ to 75$)$. To maximize the ability to detect effects of prevalence, we recruited participants from five higher prevalence states ( $>10$ confirmed cases per 10,000 residents; Florida, Georgia, Michigan, New York, and Pennsylvania), and four lower prevalence states (< 10 confirmed cases per 10,000 residents; Arizona, Kentucky, North Carolina, and Texas). Since transmission rates and Covid-19 prevalence were highest in densely populated areas (i.e. metropolitan areas), and these areas also tend to be more Democratic 
(Wilkinson, 2019), we sought to balance the voting trends of high and low prevalence groups of states (see Table 1).

Table 1

By-State Sample Sizes, Covid-19 Statistics and Voting Trends

\begin{tabular}{|c|c|c|c|c|c|}
\hline Prevalence & State & $\mathbf{N}$ & Cases $^{1}$ & Deaths ${ }^{1}$ & $\begin{array}{c}\text { Dem.:Rep. } \\
\text { Ratio }^{2}\end{array}$ \\
\hline \multirow{5}{*}{ High } & New York & 122 & 114 & 6.3 & $52: 29$ \\
\hline & Florida & 85 & 48.5 & 2.5 & $42: 39$ \\
\hline & Michigan & 105 & 29.2 & 2.1 & $45: 38$ \\
\hline & Pennsylvania & 106 & 22.1 & 0.7 & $46: 41$ \\
\hline & Georgia & 98 & 14.7 & 0.6 & $42: 40$ \\
\hline \multirow{4}{*}{ Low } & Kentucky & 68 & 6.0 & 0.3 & $41: 45$ \\
\hline & Texas & 69 & 5.8 & 0.1 & $38: 41$ \\
\hline & Arizona & 76 & 5.8 & 0.2 & $40: 42$ \\
\hline & North Carolina & 168 & 5.2 & 0.1 & $44: 39$ \\
\hline
\end{tabular}

Note. Cases and death rates are per 10000 residents on April $17^{\text {th }} 2020$ (the first day of data collection). ${ }^{1}$ : compiled from the New York Times (2020) GitHub repository. ${ }^{2}$ : Gallup (2017) poll data.

\section{Procedure}

In a $3 \times 1$ between-subjects design, participants were asked to consider one of three critical care dilemmas: Withdraw, Redirect, Driver. Participants were asked to rate the triage decision through five assessments:

1) Prescription: whether the agent (1) "should" or (0) "should not" perform the utilitarian action. 
2) Permissibility: whether it is morally permissible for the agent to:

a) do nothing: 1 = "Yes"; 0 = "No",

b) perform the utilitarian action: 1 = "Yes"; 0 = "No".

In our studies, we compute the normalized average of both dichotomous items after reverse scoring the first item (i.e., relative permissibility: $0=$ Only Inaction

Permissible, $0.5=$ Both/Neither Permissible, $1=$ Only Action Permissible) .

3) Blameworthiness: whether it is morally blameworthy for the agent to:

a) do nothing: 1 = "Not at all"; 7 = "Very much",

b) perform the utilitarian action: = "Not at all"; 7 = "Very much".

We compute the difference score, blame for action - blame for inaction, (i.e., relative blame, ranging from -6: most utilitarian, 0: equal blame, to 6: most deontological).

Following the triage dilemmas, participants completed a battery of individual difference measures. The results of these individual difference analyses are reported in Section 5.

\section{Secondary Data}

To devise a measure of local prevalence of Covid-19, we divide the recorded number of cases and deaths in each US county by its estimated population. County-level cases and deaths were obtained from the New York Times GitHub repository (github.com/nytimes/covid-19data), and population estimates were obtained from the US Census Bureau's Population Estimates Program (www.census.gov/programs-surveys/popest.html).

\section{Power Analysis}

We set $\alpha$ to .05 , and power to .80 , in order to conduct a sensitivity power analysis for logistic regression. Assuming a baseline probability of $.6\left(\hat{p}_{x=0}=.6\right)$, a sample size of 906 
participants provided sufficient statistical power to detect effects with an odds ratio (OR) $\geq 1.21$ (and $\leq 0.83$ ).

\section{Results}

\section{Scenario Differences}

A $\chi^{2}$ test revealed that prescriptive judgments differed by scenario, $\chi^{2}(2,903)=74.73, p<$ .001 , Cramer's $V=.27,95 \%$ CI $[.20, .34]$. Participants were more likely to save five patients by redirecting the oxygen tank $(\hat{p}=.87,95 \%$ CI $[.83, .91])$ than by disconnecting the oxygen tank $(\hat{p}$ $=.60,95 \%$ CI $[.55, .66]), \mathrm{OR}=4.46, \varphi=.31, z=7.24$, or fatally infecting an essential worker $(\hat{p}$ $=.62,95 \%$ CI $[.56, .67]), \mathrm{OR}=4.10, \varphi=.29, z=7.00$, both $p \mathrm{~s}_{\text {Tukey }}<.001$ (see Figure 1). Still, it is noteworthy that, by comparison to the uniform distribution, participants tended to favor even instrumental sacrifice - whether of a patient (in Withdraw) or an essential worker (in Jeopardize) in order to save a larger number of lives.

Permissibility and blame judgments also differed by scenario, permissibility: $\chi^{2}(2,903)=$ 24.59, Cramer's $V=.16,95 \%$ CI $[.11, .20]$; blame: $F(2,902)=35.77, \eta_{p}{ }^{2}=.08$, both $p$ s $<.001$. Redirecting an oxygen tank was viewed as more permissible $(\hat{p}=.69,95 \%$ CI $[.64, .74])$ than disconnecting an oxygen tank $(\hat{p}=.55,95 \% \mathrm{CI}[.49, .60]), r_{\mathrm{pb}}=.21,95 \% \mathrm{CI}[.13, .28], z=3.69$, or placing an essential worker at risk $(\hat{p}=.51,95 \% \mathrm{CI}[.64, .74]), r_{\mathrm{pb}}=.25,95 \% \mathrm{CI}[.17, .32], z$ $=4.65$, both $p \mathrm{~s}_{\text {Tukey }}<.001$. Redirecting an oxygen tank was also judged less blameworthy $(\hat{y}=-$ $0.68,95 \% \mathrm{CI}[-0.95,-0.40])$ than either disconnecting an oxygen tank $(\hat{y}=0.45,95 \% \mathrm{CI}[0.16$, $0.74])$, Cohen's $d=-0.48,95 \%$ CI [-0.64, -0.31$], t=-5.49$, or infecting an essential worker $(\hat{y}=$ $0.97,95 \%$ CI $[0.70,1.25])$, Cohen's $d=-0.67,95 \%$ CI $[-0.83,-0.51], t=-8.28$, both $p \mathrm{~s}_{\text {Tukey }}<$ .001 . 


\section{Covid-19 Prevalence}

County-level daily cases predicted participants' self-reported exposure to Covid-19, OR $=1.85,95 \%$ CI $[1.10,3.10], z=2.33, p=.020$. Participants who reported having had a close friend or family member hospitalized due to Covid-19 were more likely to reside in counties with more Covid-19 cases_-serving as validation of our prevalence assessments.

However, in multiple regression models, county-level Covid-19 prevalence had no effect on people's moral attitude toward critical care dilemmas (prevalence: all $\chi^{2} \mathrm{~s}<1.40$, all $p \mathrm{~s}>.25$; prevalencexscenario: all $\chi^{2} \mathrm{~s}<3.50$, all $\left.p \mathrm{~s}>.15\right)$. Since prevalence is greater in population-dense areas, and greater population density is associated with a Democratic political orientation, we reran the previous analyses entering participants' reported voting intentions. These supplementary analyses revealed qualitatively similar results: Prevalence of Covid-19 did not influence moral attitudes on any dependent measure (prevalence: all $\chi^{2} \mathrm{~s}<1.70$, all $p \mathrm{~s}>.15$; prevalencexscenario: all $\chi^{2} \mathrm{~s}<3.05$, all $\left.p \mathrm{~s}>.20\right)$. Figure 1 displays prescriptive judgments by scenario and voting intention, separately for low- and high- prevalence states.

\section{Covid-19 Threat Severity}

We included a two-item measure of Covid-19 severity beliefs (Cronbach's $\alpha=.73$ ) described in further detail in the 'Individual Difference Analyses section. This measure revealed a weak effect of perceived severity on moral attitudes toward critical care dilemmas: In a multiple logistic and linear regressions, viewing Covid-19 as a severe threat was associated with support for utilitarian triage decisions $(O R=1.14, z=2.00, p=.045)$, and with judging that utilitarian action in triage contexts is more permissible $(\mathrm{OR}=1.18, t=2.18, p=.030)$ and marginally less blameworthy $\left(B=-0.12, t=-1.69, p=.073, \eta_{p}{ }^{2}=.003\right)$ than inaction.

\section{Figure 1}


Prescriptive Judgments in Triage Dilemmas by Prevalence and Voting Intention

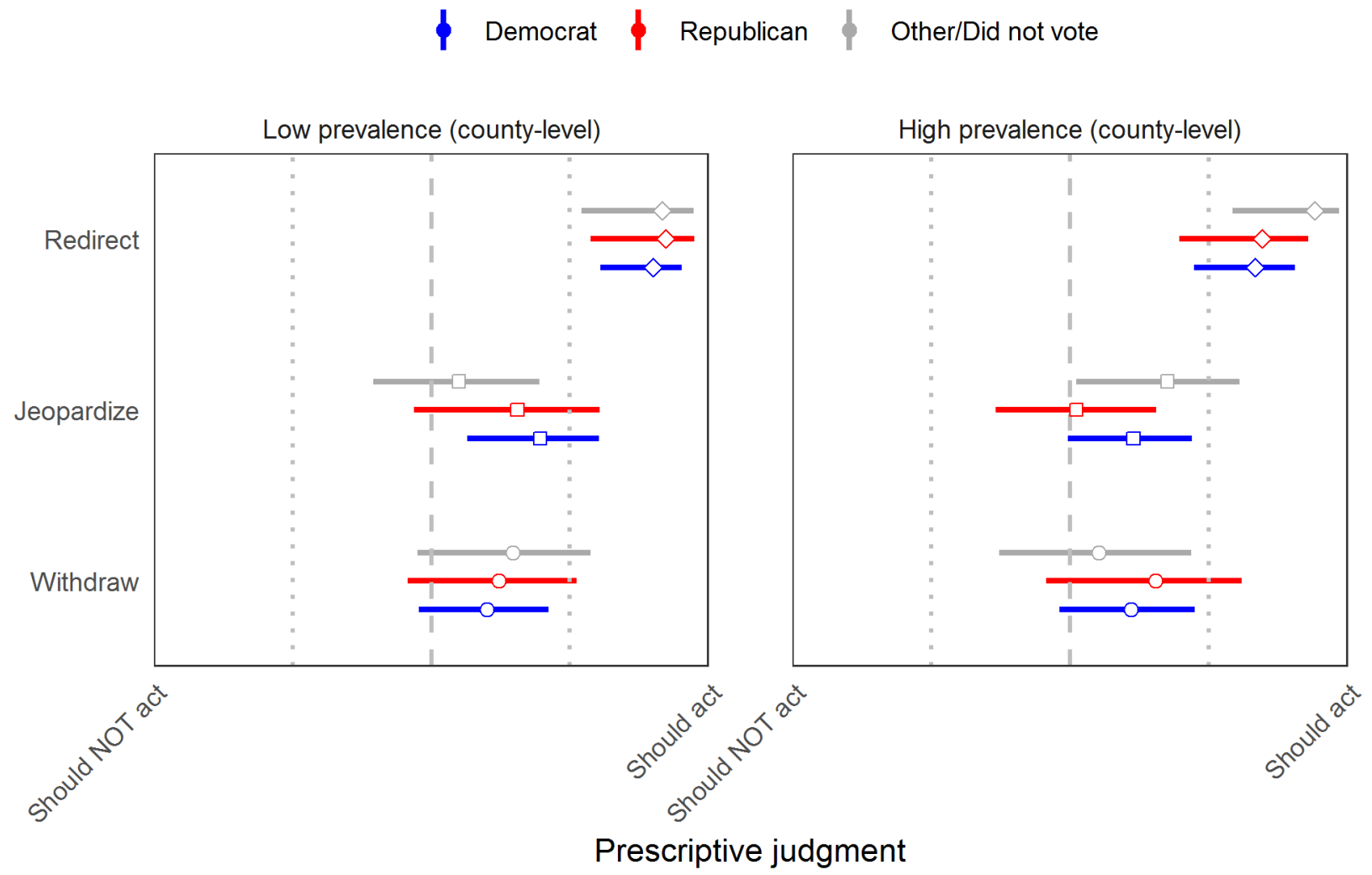

\section{Discussion}

Participants reported relatively favorable attitudes toward utilitarian resolutions of critical care dilemmas (see also Wilkinson et al., 2020). The clearest pattern emerged for collateral sacrifice (i.e., in the Redirect scenario): Participants prescribed utilitarian action, and judged it relatively more permissible and less blameworthy than inaction. For instrumental sacrifice, participants continued to prescribe utilitarian action (in the Withdraw and Jeopardize scenarios), despite rating it somewhat more blameworthy than inaction (and comparably permissible). These attitudes were unrelated to local prevalence of Covid-19, though they appeared to be weakly associated with beliefs about coronavirus severity. 


\section{Study 2}

The observation of broad support for utilitarian interventions in Study 1 raises the possibility that the Covid-19 pandemic has precipitated a shift in people's moral attitudes regarding human life. In Study 2, we examine whether the onset of the Covid-19 pandemic increased support for utilitarian sacrifice more broadly. To evaluate this hypothesis, we ran a two-wave longitudinal study contrasting people's views about utilitarian sacrifice prior to versus during the Covid-19 pandemic.

\section{Methods}

\section{Materials}

In Study 2, we drew on a diverse set of traditional moral dilemmas, adapted from previous studies in moral psychology (e.g., Koenigs et al., 2007). Four scenarios involved instrumental sacrifice (i.e., death as a means to the greater good; as in Withdraw), and four scenarios involved collateral sacrifice (i.e., death as a side effect of pursuing the greater good; as in Redirect). Importantly, none of the dilemmas employed in Study 2 alluded to the Covid-19 pandemic, or described critical care scenarios.

\section{Participants}

905 crowdworkers ( $48 \%$ women; age: $M=40.5, S D=13.6$, range $=18$ to 81 ) were recruited at two time points one year apart: May of 2019 (pre-pandemic $n=395$ ), and May of 2020 (mid-pandemic $n=513$ ).

\section{Procedure}

In a 2 (period: pre, mid) $\times 2$ (condition: instrumental, collateral) between-subjects design, participants were asked to consider a traditional moral dilemma involving either instrumental or collateral sacrifice. They then made prescriptive and permissibility judgments (but not 
blameworthiness judgments), as in Study 1. Following the moral dilemma, participants completed a battery of individual difference measures - the results of which are reported in the Section titled 'Individual Difference Analyses'.

\section{Power Analysis}

We set $\alpha$ to .05 , and $\beta$ to .20 (power to $80 \%$ ), in order to conduct a sensitivity power analysis for logistic regression. A sample size of 905 participants (and assuming $\hat{p}_{\text {pre }}=.60$ ) provided sufficient statistical power to detect effects with an odds ratio $(\mathrm{OR}) \geq 1.21$ (and ORs $\leq$ $0.83)$.

\section{Results}

We entered period, condition and the two-way interaction between period and condition in mixed-effects regression models (with scenario as a random effect). Through model selection, we observed no main effect of period either on prescriptive judgments, $\chi^{2}(d f=1)=0.00, p=.97$, or on permissibility judgments, $F(1,896)=0.22, p=.73$. In other words, the marginal effects of period on prescriptive judgments $\left(\hat{p}_{\text {pre }}=.62,95 \%\right.$ CI $[.48, .75]$; vs. $\hat{p}_{\text {mid }}=.63,95 \%$ CI $\left.[.49, .75]\right)$, $\mathrm{OR}=1.02, z=0.11, p=.91$, and permissibility judgments $\left(\hat{y}_{\text {pre }}=-0.16,95 \% \mathrm{CI}[-1.20,0.87]\right.$; vs $\left.\hat{y}_{\text {mid }}=-0.10,95 \% \mathrm{CI}[-1.13,0.93]\right), B=0.06, \mathrm{z}=0.06, p=.95$, were non-significant.

Furthermore, a Bayesian analysis provided strong evidence for the absence of period effects (prescriptive: $\mathrm{BF}_{01}=13.84 ;$ permissibility: $\mathrm{BF}_{01}=12.92$ ).

We also found no period $\times$ condition interaction effect on relative permissibility judgments, $F(1,896)=0.72, p=.63$ - though we observed a marginally significant trend for prescriptive judgments, $\chi^{2}(d f=1)=2.95, \mathrm{OR}=1.67, p=.086$ (see Figure 2 ). The simple effects of period on prescriptive judgments were statistically non-significant (collateral: $\mathrm{OR}=0.76, z=$ 
$-1.27, p_{\text {Tukey }}=.20 ;$ instrumental: $\left.\mathrm{OR}=1.27, z=1.19, p_{\text {Tukey }}=.23\right)$, and absent from a Bayesian perspective (collateral: $\mathrm{BF}_{01}=9.54$; instrumental: $\mathrm{BF}_{01}=8.95$ ).

\section{Propensity Score Matching}

Stay-at-home orders, and shifts in childcare duties and employment status, could have brought about changes in crowdworkers' demographic profile from May 2019 to May 2020. To evaluate this concern, we first estimate propensity scores (Rosenbaum \& Rubin, 1983) for each participant: i.e., the predicted probability of participating in the study during the pandemic rather than before. Indeed, a multiple logistic regression (with age, gender, educational attainment and native language status) revealed significant differences in the demographic profile of our two samples, omnibus $\chi^{2}(d f=4)=17.86, p=.001$. Specifically, whereas age $(\mathrm{OR}=1.01, z=1.67, p$ $=.095)$, gender $(\mathrm{OR}=0.83, z=-1.35, p=.18)$, and native language $(\mathrm{OR}=0.59, z=-1.16, p=$ .25) differences were small and non-significant, educational attainment was a clear predictor of participation during the pandemic (vs. before), $\mathrm{OR}=1.18, z=3.36, p=.001$.

A nearest-neighbor matching algorithm yielded 395 matched pairs, which showed good balance on all four covariates: age ( $\mathrm{OR}=1.00, z=0.54, p=.59)$, gender $(\mathrm{OR}=1.07, z=0.44, p$ $=.66)$, native language $(\mathrm{OR}=1.25, z=0.40, p=.69)$, and educational attainment $(\mathrm{OR}=1.05, z$ $=0.97, p=.33$ ). In this matched dataset, the main effect of period remained non-significant (prescription: $\chi^{2}[d f=1]=0.00, \mathrm{OR}=1.00, p=.99, \mathrm{BF}_{01}=11.05$; permissibility: $F[1,781]=$

$0.21, p=.64, \mathrm{BF}_{01}=12.36$ ), as did its interaction with condition (prescription: $\chi^{2}[d f=1]=1.98$, $\mathrm{OR}=1.55, p=.16, \mathrm{BF}_{01}=3.31 ;$ permissibility: $\left.F[1,781]=0.51, p=.47, \mathrm{BF}_{01}=7.31\right)$.

\section{Discussion}

The results of Study 2 suggest that the Covid-19 pandemic has not affected moral attitudes toward utilitarian sacrifice in general (see also Francis, \& McNabb, 2021). Therefore, 
elevated utilitarian tendencies in Study 1 cannot straightforwardly be attributed to a period effect. Next, we turn to the realism hypothesis.

\section{Study 3}

To investigate the realism hypothesis, we conducted a third study during the Covid-19 pandemic. According to this hypothesis, the psychological salience of Covid-19 could shift moral attitudes toward scenarios describing triage of coronavirus patients. Specifically, psychological realism may render triage dilemmas more engaging than hypothetical dilemmas and, as a result, elicit different cognitive processes (see also Francis et al., 2016 2017; Patil et al., 2014). Such a result would imply certain limits on the ecological validity of traditional moral dilemma research (Baumann et al. 2014).

\section{Methods}

\section{Materials}

For this study, we devised matched pairs of vignettes involving either instrumental or collateral sacrifice. In each pair, one vignette (taken from Study 1: i.e., Redirect or Withdraw) involved triage of critical care resources to treat Covid-19 patients, and another involved a tightly-matched, control dilemma about a house fire. More specifically, in the Collateral condition, a fire truck is rerouted from one smaller house fire to a larger house fire to save a larger number of lives. In the Instrumental condition, a fire truck ceases to extinguish a smaller house fire in order to save a larger number of lives in a larger, nearby fire.

\section{Participants}

A minimum sample size of 400 (or 100 per group) was decided before any data collection or analysis. 487 crowdworkers ( $44 \%$ women; age: $M=43.5, S D=14.3$, range $=21$ to 79 ) were recruited in May of 2020. 


\section{Procedure}

In a 2 within- (realism: triage, control) $\times 2$ between- (condition: personal, impersonal) $\times$ 2 between- (order: triage-first, control-first) subjects design, participants were randomly assigned to one of four groups. In every group, participants viewed both a triage and a control (i.e., house fire) dilemma, and we manipulated the order in which the dilemmas appeared, as well as whether they involved instrumental or collateral sacrifice of a human life.

\section{Power Analysis}

We set $\alpha$ to .05 , and $\beta$ to .20 (power to $80 \%$ ), in order to conduct a sensitivity power analysis for logistic regression. A sample size of 487 participants (and setting $\hat{p}_{\text {control }}=.60$ ) provided sufficient statistical power to detect effects with an odds ratio (OR) $\geq 1.30$ (and ORs $\leq$ $0.77)$.

\section{Results}

\section{First-Trial Analysis}

In a logistic regression model, we entered realism, condition and the two-way interaction between realism and condition as predictors of prescriptive judgments. A model comparison revealed effects of condition, $\chi^{2}(d f=1)=15.74$, OR $=2.19, z=3.92$, and of the realism $\times$ condition interaction, $\chi^{2}(d f=1)=16.92$, $\mathrm{OR}=5.49, z=4.00$, both $p \mathrm{~s}<.001$. No main effect of realism was observed, $\chi^{2}(d f=1)=2.22, \mathrm{OR}=1.34, \mathrm{z}=1.48, p=.14$.

Figure 2 displays the simple effects in the realism×condition interaction: Participants in the Redirect condition were more likely to prescribe utilitarian action in a triage context $(\hat{p}=.87$, $95 \% \mathrm{CI}[.80, .92])$ than in a control context $(\hat{p}=.65,95 \% \mathrm{CI}[.57, .73]), \mathrm{OR}=3.64, z=3.88$, $p_{\text {Tukey }}<.001-$ which corresponds to decisive evidence in Bayesian terms $\left(\mathrm{BF}_{10}=371.53\right)$. The difference in the Withdraw condition was not statistically significant $\left(\hat{p}_{\text {triage }}=.53,95 \%\right.$ CI $[.44$, 
$.63]$; vs. $\left.\hat{p}_{\text {control }}=.64,95 \% \mathrm{CI}[.55, .71]\right), \mathrm{OR}=0.63, t=-1.55, p_{\text {Tukey }}=.12$-which constitutes only anecdotal evidence in favor of the null $\left(\mathrm{BF}_{01}=2.25\right)$.

This pattern of results was mirrored in the ratings of blame: A two-way ANOVA revealed effects of condition, $F(1,479)=9.49, p=.002, \eta_{p}{ }^{2}=.02$, realism, $F(1,479)=4.44, p=$ $.036, \eta_{p}{ }^{2}=.01$, and of the realism $\times$ condition interaction, $F(1,479)=17.78, p<.001, \eta_{p}{ }^{2}=.05$. Participants in the Redirect condition assigned less blame for utilitarian action in a triage context $(-1.03,95 \%$ CI $[-1.41,-0.65])$ than in a control context $(0.17,95 \%$ CI $[-0-19,0.54]), t=4.46$, $p_{\text {Tukey }}<.001$, Cohen's $d=-0.64,95 \%$ CI [-0.91, -0.38]. The difference in the Withdraw condition was not statistically significant (triage: $0.42,95 \%$ CI [0.02, 0.81 ; vs. control: 0.00 , $95 \%$ CI $[-0.37,0.37]), t=-1.53, p_{\text {Tukey }}=.13$, Cohen's $d=0.18,95 \%$ CI [-0.08, 0.44].

Relative permissibility judgments revealed a different pattern: We observed more modest effects of condition, $\chi^{2}(d f=1)=5.41, \mathrm{OR}=1.08, p=.020$, and of the realism $\times$ condition interaction, $\chi^{2}(d f=1)=7.18, \mathrm{OR}=1.16, p=.007$. No main effect of realism was observed, $\chi^{2}(d f$ $=1)=0.24, \mathrm{OR}=1.02, p=.62$. This time, utilitarian action resulting in collateral death was not judged more permissible in a triage context $(\hat{p}=.66,95 \%$ CI $[.60, .73])$ than in a control context $(\hat{p}=.60,95 \% \mathrm{CI}[.54, .66]), t=1.53, p_{\text {Tukey }}=.13, r_{\mathrm{pb}}=.10,95 \% \mathrm{CI}[-.02, .22]$. However, utilitarian action in the Instrumental condition was deemed less permissible in a triage context $(.50,95 \%$ CI $[.44, .57])$ than in a control context $(.60,95 \%$ CI $[.55, .66]), t=-2.26, p_{\text {Tukey }}=.024$, $r_{\mathrm{pb}}=-.10,95 \%$ CI [-.22, -.03].

\section{Figure 2}

Prescriptive Judgments in Studies 1, 2 and 3. Heightened Endorsement of Collateral Sacrifice (Left) is Explained by an Effect of Realism (Right), not of Period (Center) 


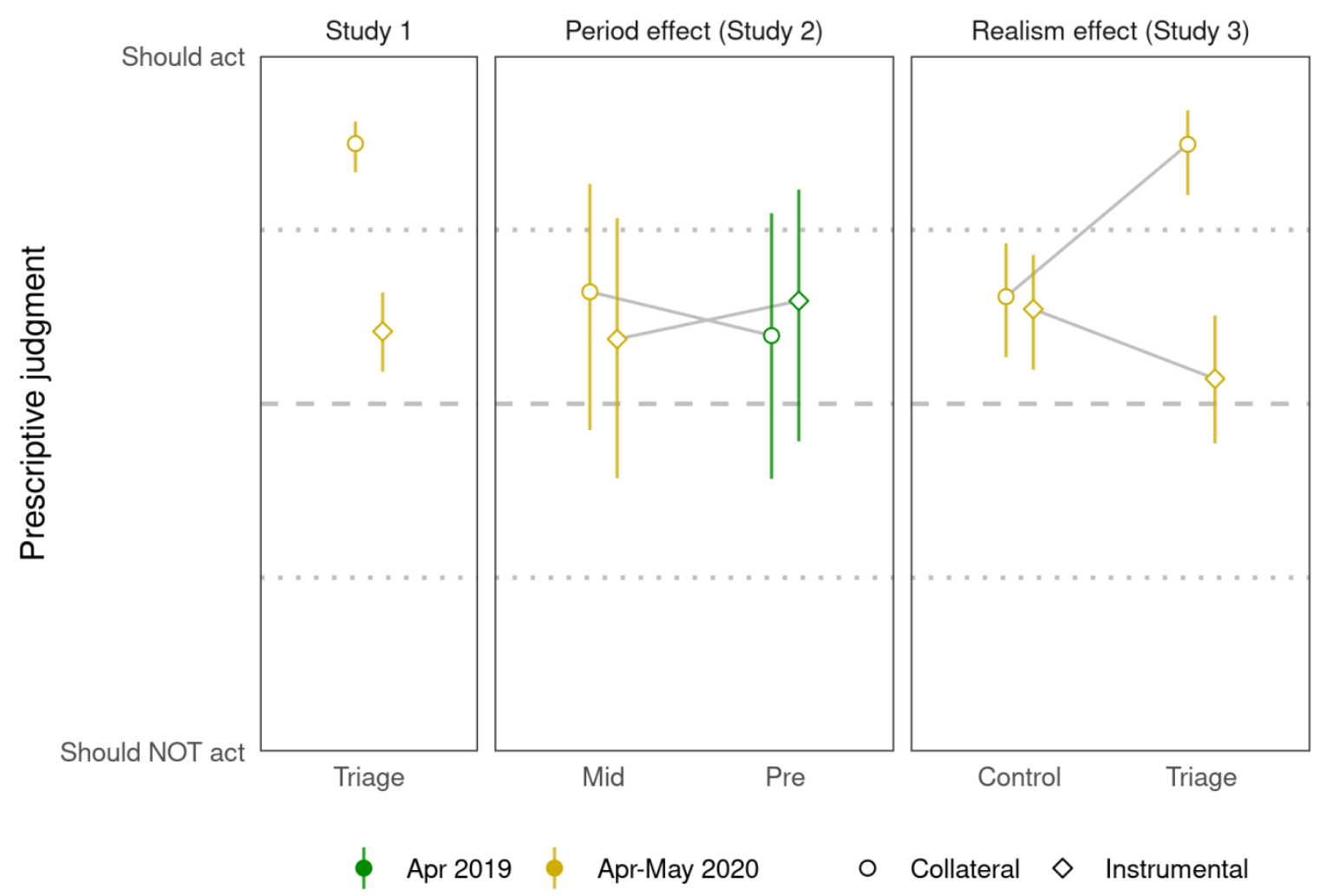

\section{Order Effect}

Through model comparison, we observed a two-way interaction between condition and order for every dependent measure (prescription: $\chi^{2}[d f=1]=13.20, \mathrm{OR}=3.88, p<.001$; permissibility: $\chi^{2}[d f=1]=4.49, \mathrm{OR}=1.95, p=.034$; blame: $\mathrm{F}(1,480)=14.84, p<.001, \eta_{p}{ }^{2}=$ .03). At a broad level, judgments of Collateral sacrifice depended on the order in which the dilemmas were presented (see Figure 3): When the triage dilemma was presented first, participants were more likely to report that agents should perform the utilitarian action across contexts (triage: $z=3.65, \mathrm{OR}=12.23, p_{\text {Tukey }}<.001 ;$ control: $z=2.79, \mathrm{OR}=5.64, p_{\text {Tukey }}=.005$ ), that inaction was blameworthy in both contexts (triage: $t=-3.20$, Cohen's $d=-0.45,95 \%$ CI [$0.71,-0.20], p_{\text {Tukey }}=.001 ;$ control: $t=-4.61$, Cohen's $d=-0.65,95 \%$ CI $[-0.95,-0.39], p_{\text {Tukey }}<$ .001 ), and that utilitarian action in triage contexts was permissible (triage: $z=2.48, \mathrm{OR}=1.96$, $p_{\text {Tukey }}=.013$; whereas control: $z=1.27, \mathrm{OR}=1.29, p_{\text {Tukey }}=.21$ ). 


\section{Figure 3}

Order Effects in Study 3. Marginal Effect of Triage-First Order by Condition.

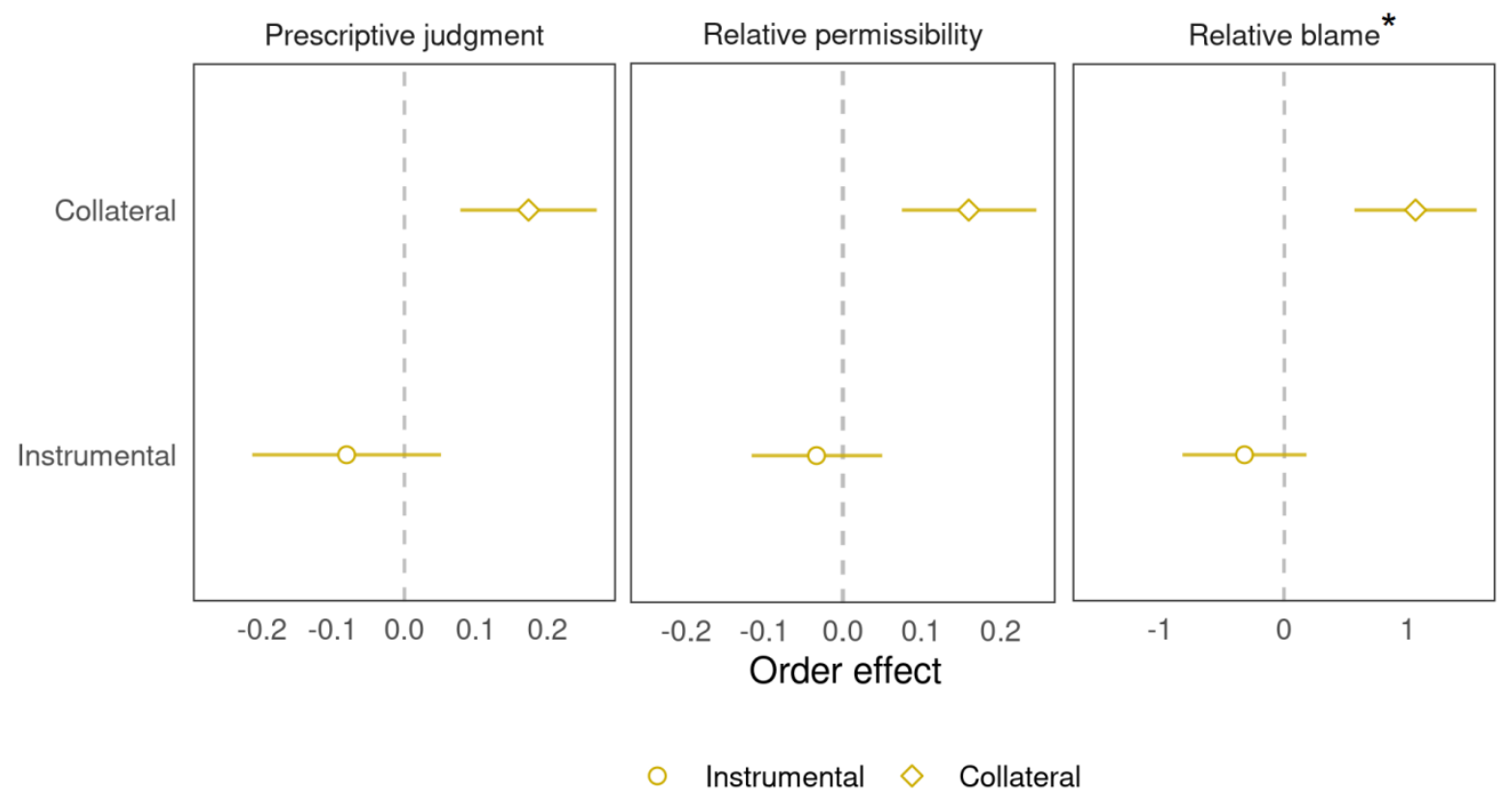

Note. *: The signs of the relative blame effects have been reversed in this figure. A positive effect indicates heightened utilitarianism in every panel.

\section{Discussion}

The results of Study 3 suggested that heightened utilitarianism in Study 1 (also observed in Wilkinson et al., 2020) may have arisen from the psychological realism of ICU triage dilemmas amidst the Covid-19 pandemic. Participants demonstrated more utilitarian attitudes when judging dilemmas involving critical care triage than when considering structurally analogous, control dilemmas - at least in circumstances demanding collateral sacrifice. This effect then shaped participants' moral attitudes in the subsequent trial, resulting in elevated utilitarian attitudes toward control dilemmas when these were preceded by psychologically realistic, triage dilemmas. In sum, we obtained evidence for the absence of a period effect in Study 2 (through Bayesian analyses), but evidence in favor of a realism effect in Study 3. 


\section{Individual Difference Analyses}

Attitudes towards the Covid-19 pandemic have been shown to vary considerably with political ideology. Survey evidence reveals significant differences across party lines on numerous measures: the belief that "powerful people intentionally planned the Covid-19 outbreak" (Republican: 34\% v. Democrats 18\%, Pew Research, 2020a), and that Covid-19 constitutes a major public health threat (Republicans: 46\% v. Democrats: 85\%, Pew Research, 2020c), as well as the fear of unwittingly spreading the virus (Republicans: $45 \%$ v. Democrats: $77 \%$ ) or contracting it (Republicans: 35\% v. Democrats: 64\%; Pew Research, 2020b).

Given the pronounced differences in partisan views about the severity and origin of Covid-19, as well as in compliance with public health recommendations (Gollwitzer et al., 2020), one might also expect disagreement between liberals and conservatives concerning critical care triage. In our studies, we sought to replicate evidence of political polarization concerning the origin and severity of Covid-19, and to ask whether polarization extends to the ethics of critical care triage (Hunter, 1991).

Additionally, to deepen our understanding of the role of experimental realism in moral affect, we administered individual difference measures of empathy (Davis, 1983) and utilitarian motivation (Kahane et al., 2018). Here we report aggregate analyses examining their associations with moral attitudes toward triage dilemmas.

\section{Measures}

\section{Interpersonal Reactivity Index}

Participants in Studies 1, 2 and 3 completed the empathic concern (Cronbach's $\alpha$ s $=.87$, $.87, .86$ ) and perspective-taking (Cronbach's $\alpha$ s $=.83, .86, .84$ ) subscales of the Interpersonal Reactivity Index (Davis, 1983). Scores on the empathic concern subscale have been previously 
associated with weaker utilitarian tendencies on hypothetical moral dilemmas (Gleichgerrcht \& Young, 2013; also Hannikainen et al., 2018).

\section{Oxford Utilitarianism Scale}

Participants in Studies 1, 2 and 3 completed the nine-item Oxford Utilitarianism Scale (Kahane et al., 2018), composed of two subscales: instrumental harm (Cronbach's $\alpha$ s $=.77, .81$, .77 ) and impartial beneficence (Cronbach's $\alpha \mathrm{s}=.76, .81, .79$ ). Support for utilitarian trade-offs in hypothetical moral dilemmas has been associated primarily with scores on the instrumental harm subscale (Kahane et al., 2018).

\section{Social and Economic Conservatism Scale}

Participants in Studies 1 and 3 completed the twelve-item Social and Economic Conservatism Scale (Everett, 2013; Cronbach's $\alpha$ s $=.87, .88$ ). Participants reported their feelings toward twelve sociomoral issues that distinguish liberal from conservative ideology (e.g., patriotism, religion, welfare benefits [reversed], or gun ownership), on a scale anchored at 1: 'Negative' to 7: 'Positive'.

\section{Coronavirus Threat Severity}

To assess participants' beliefs about the severity of coronavirus, participants were asked to answer two questions in Studies 1 and 3 (Cronbach's $\alpha$ s $=.73, .81$ ): (1) "What is your general attitude towards the current coronavirus situation?", ranging from 1: 'People are completely exaggerating the danger' to 7: 'This is a very serious situation'; (2) 'Do you think a lockdown as it is carried out in many countries is warranted?", ranging from 1: 'No, I completely disagree with the lockdown' to 7: 'Yes, I completely agree with the lockdown'. 


\section{Coronavirus Conspiracy Beliefs}

We also introduced a novel five-item assessment of conspiratorial thinking about coronavirus (Cronbach's $\alpha \mathrm{s}=.93, .93$ ), adapted from the Generic Conspiracist Beliefs Scale (Brotherton, French, \& Pickering, 2013). For each item (e.g., "The spread of coronavirus has been the result of the deliberate, concealed efforts of some governments and scientists"), participants reported their level of agreement from 1: 'Strongly disagree' to 7: 'Strongly agree'.

\section{Power Analyses}

We set $\alpha$ to .05 , and $\beta$ to .20 (power to $80 \%$ ), in order to conduct sensitivity power analyses for pairwise correlation.

Traditional Dilemmas. 509 participants (in Study 2 mid-pandemic wave) judged a traditional dilemma and completed the individual difference measures. This sample provided sufficient statistical power (80\%, with $\alpha=.05)$ to detect correlations of $|r| \geq .12$.

Triage Dilemmas. 1132 participants judged a triage dilemma (as first trial; in Studies 1 and 3) and completed the individual difference measures. This sample provided enough statistical power $(80 \%$, with $\alpha=.05)$ to detect correlations of $|r| \geq .08$.

\section{Results}

\section{Empathy in Triage versus Traditional Dilemmas}

We partially reproduced an association between empathic concern and deontological judgment (Gleichgerrcht \& Young, 2013) in the context of standard hypothetical dilemmas: Greater empathic concern predicted reduced permissibility of utilitarian action (relative to inaction $), r(509)=-.09,95 \% \mathrm{CI}[-.18,-.01], p=.034$. No corresponding effect emerged for prescriptive judgments or with the perspective-taking subscale (see Table 1). 
In triage dilemmas, we also found an association between empathic concern and permissibility judgments - though in the opposite direction, $r(1132)=.09,95 \%$ CI $[.03, .14], p$ $=.003$ (see Table 2). In other words, empathic individuals were more likely to view utilitarian triage as permissible, but utilitarian action in hypothetical dilemmas as impermissible.

Furthermore, the effect of empathic concern on permissibility judgments was moderated by type of dilemma (empathic concern $\times$ dilemma type: $\chi^{2}[d f=1]=12.28, O R=1.89, p=.001$ ). Partialing out the effect of scenario in a multiple regression, confirmed that the marginal slope of empathic concern in traditional dilemmas was negative (as in prior research; $O R=0.66$, partial $r$ $=-.12)$ but positive in triage dilemmas $(O R=1.25$, partial $r=.06)$ —and these effects significantly differed, $z=3.52, p<.001$. Still, generally speaking, the role of self-reported affect appeared to be fickle in our studies.

Table 2

Pairwise Correlation Between IRI Subscales and Moral Judgments in Traditional (Above Diagonal) and Triage (Below Diagonal) Dilemmas

\begin{tabular}{lcccc} 
Ns $=1132$ (below); 509 (above). & $(1)$ & $(2)$ & $(3)$ & $(4)$ \\
\hline (1) Empathic concern & - & $\begin{array}{c}.64 * * * \\
{[.59, .69]}\end{array}$ & $\begin{array}{c}-.01 \\
{[-.07, .066]}\end{array}$ & $\begin{array}{c}\mathbf{- . 0 9} * \\
{[-.18,-.01]}\end{array}$ \\
\hline (2) Perspective-taking & $.60 * * *$ & & .05 & -.01 \\
& {$[.56, .63]$} & - & {$[-.04, .14]$} & {$[-.09, .08]$} \\
\hline (3) Prescriptive judgment & .04 & .05 & & $.60 * * *$ \\
& {$[-.02, .10]$} & {$[-.01, .10]$} & & {$[.56, .64]$} \\
\hline (4) Relative permissibility &. $\mathbf{0 9} * * *$ & $.07 *$ & $.63 * * *$ & \\
\hline (5) Relative blame & {$[.03, .14]$} & {$[.01, .13]$} & {$[.59, .66]$} & - \\
\hline
\end{tabular}


Note. *: $p<.05 ; * *: p<.01 ; * * *: p<.005$. Bold cells indicate significant correlations between

IRI subscales and moral attitudes.

Utilitarian Beliefs in Triage versus Traditional Dilemmas

Both facets of utilitarianism correlated with judgments of both triage and hypothetical dilemmas (see Table 3).

Table 3

Pairwise Correlation Between OUS Subscales and Moral Judgments in Traditional (Above Diagonal) and Triage (Below Diagonal) Dilemmas

Ns $=1132$ (below); 509 (above).

(1) Instrumental harm

(2) Impartial beneficence $.29 * * *$

(2) Impartial beneficence

$[.24, .34]$
(2)

(3)

$.37 * * *$

$[.29, .44]$

$[.27, .42]$
$.40 * * *$

$[.32, .47]$

$.12 * *$

$.10 *$

$[.03, .20]$

$[.01, .18]$

$.60 * * *$

(3) Prescriptive judgment

$.26 * * *$

$[.21, .31]$

$[.12, .23]$ $[.56, .64]$

\begin{tabular}{lcccc}
\hline (4) Relative permissibility & $\mathbf{. 1 4} * * *$ & $\mathbf{. 1 0} * * *$ & $.63 * * *$ & - \\
& {$[.08, .20]$} & {$[.04, .15]$} & {$[.59, .66]$} & \\
\hline \multirow{2}{*}{ (5) Relative blame } & $\mathbf{- . 1 6} * * *$ & $\mathbf{- . 1 1} * * *$ & $-.38 * * *$ & $-.40 * * *$ \\
& {$[-.22,-.11]$} & {$[-.16,-.05]$} & {$[-.43,-.33]$} & {$[-.45,-.35]$} \\
\hline
\end{tabular}

Note. *: $p<.05 ; * *: p<.01 ; * * *: p<.005$. Bold cells indicate significant correlations between

OUS subscales and moral attitudes.

A series of regression models uncovered significant differences in the role of utilitarian beliefs across dilemma types: First, instrumental harm and impartial beneficence differentially predicted prescriptive judgments across dilemma types (IH×dilemma type: $\chi^{2}[d f=1]=5.12$, OR $=1.28, p=.024$; IB $\times$ dilemma type: $\left.\chi^{2}[d f=1]=8.30, \mathrm{OR}=1.37, p=.004\right)$. Specifically, instrumental harm beliefs better predicted judgments about traditional dilemmas $(O R=1.96$, 
partial $\left.r_{\mathrm{pb}}=.37\right)$ than about triage dilemmas $\left(O R=1.53\right.$, partial $\left.r_{\mathrm{pb}}=.22\right), z=-2.26, p=.024$. In turn, impartial beneficence beliefs predicted judgments about triage dilemmas $(O R=1.25$, partial $\left.r_{\mathrm{pb}}=.10\right)$, but did not predict judgments of traditional dilemmas $\left(O R=0.91\right.$, partial $\left.r_{\mathrm{pb}}=-.05\right)-$ and these coefficients statistically differed from each other, $z=2.88, p=.004$.

Second, utilitarian beliefs differentially predicted permissibility judgments across dilemma types (IH×dilemma type: $\chi^{2}[d f=1]=13.92, O R=1.45, p<.001$; IB $\times$ dilemma type: $\left.\chi^{2}[d f=1]=3.00, O R=0.84, p=.083\right)$. Instrumental harm beliefs better predicted judgments of permissibility in traditional dilemmas $(O R=1.74$, partial $r=.42)$ than in triage dilemmas $(O R=$ 1.17, partial $r=.14$ ) -and these effects statistically differed from each other, $z=-5.68, p<.001$. Meanwhile, impartial beneficence predicted permissibility judgments for triage dilemmas $(O R=$ 1.28, partial $r=.14$ ) thought not traditional dilemmas $(O R=1.08$, partial $r=.04)$; and the difference between these marginal trends approached significance, $z=1.73, p=.083$.

Third, impartial beneficence independently predicted judgments of relative blame in triage dilemmas $(B=-0.01, t=-2.22, p=.026$, partial $r=.07)$, even after controlling for the effect of instrumental harm beliefs $(B=-0.02, t=-4.19, p<.001$, partial $r=.12)$. We did not include the blame dependent measures in Study 2, precluding the comparison across dilemma types.

Collectively, these results show that views about triage dilemmas depend upon both instrumental harm beliefs and impartial beneficence — whereas attitudes toward traditional dilemmas are shaped primarily (or even solely) by beliefs about instrumental harm.

\section{Ideological Disagreements on Triage Dilemmas}

The 12-item SECS scale discriminated between Democrats $(M=4.13, \mathrm{SD}=0.93)$, Republicans $(M=5.64, \mathrm{SD}=0.78)$ and Independents $(M=4.69, \mathrm{SD}=0.99)$, all pairwise $p$ s < 
.001. We observed clear associations between political ideology and general attitudes toward Covid-19: Conservatives were more likely to hold conspiratorial beliefs about Covid-19, $r(1132)$

$=.20,95 \% \mathrm{CI}[.14, .26]$, while liberals were more likely to treat Covid-19 as a serious threat, $r(1130)=-.31,95 \%$ CI $[-.36,-.26]$, both $p$ s $<.001$.

Despite replicating ideological disagreements concerning the truth about Covid-19, we observed few moral disagreements between liberals and conservatives (see Table 4): No differences arose in either the Jeopardize or Reroute scenarios; meanwhile, in the Withdraw scenario, conservatives were more likely to blame the utilitarian agent than were liberals (see also Luke \& Gawronski, 2021; Hannikainen, Miller \& Cushman, 2017)—but no parallel differences emerged for permissibility or prescriptive judgments. Bayesian model comparisons confirmed that liberals and conservatives revealed robust disagreement concerning the truth about Covid-19 $\left(\mathrm{BF}_{10} \mathrm{~s}>10^{11}\right)$, but tended to agree in their moral attitudes toward triage dilemmas $\left(\mathrm{BF}_{01} \mathrm{~S}>5\right.$; except regarding permissibility, which was inconclusive $\left.\mathrm{BF}_{10}<3\right)$.

\section{Table 4}

Ideological Differences in Moral Attitudes, Conspiratorial Thinking and Perceived Severity

\begin{tabular}{lcccc}
\hline & Withdraw & Jeopardize & Redirect & $\begin{array}{c}\text { Main effect of } \\
\text { SECS score } \\
\text { (BF) }\end{array}$ \\
& 386 & 309 & 433 & 1128 (pooled) \\
\hline (1) Prescriptive judgment & -.09 & .00 & -.07 & 5.92 \\
& {$[-.18, .02]$} & {$[-.11, .11]$} & {$[-.16, .03]$} & $($ null) \\
\hline (2) Relative permissibility & -.02 & .02 & -.01 & 15.22 \\
& {$[-.12, .08]$} & {$[-.10, .13]$} & {$[-.11, .08]$} & $($ null) \\
\hline (3) Relative blame & $-.19 * * *$ & -.06 & -.00 & 2.21 \\
& {$[-.28,-.09]$} & {$[-.17, .05]$} & {$[-.10, .09]$} & $($ alt. $)$ \\
\hline
\end{tabular}




\begin{tabular}{lcccc}
\hline (4) Corona-threat & $\mathbf{- . 2 4} * * *$ & $\mathbf{- . 3 6} * * *$ & $\mathbf{- . 3 3} * * *$ & $8.31 \times 10^{27}$ \\
& {$[-.33,-.14]$} & {$[.-45,-.26]$} & {$[.-42,-.25]$} & $($ alt. $)$ \\
\hline (5) Corona-conspiracy & $\mathbf{. 1 4} * *$ & $\mathbf{2 9} * * *$ & $\mathbf{. 1 9} * * *$ & $5.99 \times 10^{11}$ \\
& {$[-.28,-.09]$} & {$[.18, .39]$} & {$[.10, .28]$} & $($ alt. $)$ \\
\hline
\end{tabular}

Note. $*: p<.05 ; * *: p<.01 ; * * *: p<.005$. null: in support of null model; alt:: in support of alternative model. Bold cells indicate significant correlations with SECS scores.

\section{Discussion}

First, we found limited effects of empathy, which could stem from the self-reported nature of our measures. Importantly, the effect of empathic concern—where present—reversed from traditional, trolley-type contexts to psychologically realistic, triage contexts: i.e., underlying deontological judgments in traditional dilemmas, but utilitarian judgments in triage dilemmas.

Second, attitudes toward traditional dilemmas were linked to participants' abstract attitudes toward instrumental harm (in line with Kahane et al., 2015 2018), whereas attitudes toward dilemmas involving critical care were also tied to participants' tendency toward impartial beneficence. Thus, for psychologically realistic dilemmas, prosocial attitudes including affective empathy and impartial beneficence can also be predictors of greater utilitarian tendencies (in contrast to previous work on trolley-type dilemmas; see e.g., Bartels \& Pizarro, 2011; Gleichgerrcht \& Young, 2013).

Third, we replicated the association between political ideology and beliefs about the origin and severity of Covid-19—revealing substantial polarization. Yet, in their moral attitudes toward critical care triage, liberals and conservatives appeared to be largely in agreement.

\section{General Discussion}

Our study documented heightened utilitarianism in diverse locations throughout the United States in reaction to dilemmas describing ICU triage scenarios. These attitudes appeared 
not to depend on the prevalence of Covid-19 confirmed positives; but, rather, arose homogeneously across high and low prevalence regions (Study 1). We then reasoned that this effect could stem from a period effect, i.e., heightened utilitarianism following the onset of the Covid-19 pandemic — yet our evidence spoke against period-driven change in moral judgment (Study 2). Alternatively, the effect could be due to the psychological realism of critical care dilemmas. Our next follow-up (Study 3) lent support to this interpretation, demonstrating a selective tendency to favor utilitarian resolutions of triage dilemmas, relative to tightly-matched dilemmas unrelated to the Covid-19 pandemic.

As such, our findings dovetail with prior evidence showing that promoting experimental realism amplifies_-rather than dampens_-utilitarian tendencies (Patil et al., 2014; Francis et al., 2016, 2017, see also Baumann et al. 2012). This result cannot easily be explained by theories that link utilitarian tendencies to sub-clinical deficits in affect (Bartels \& Pizarro, 2011). Our moderation analyses pointed toward a distinct explanation: First, affective engagement was linked to utilitarian responses in triage dilemmas (but deontological responses to traditional dilemmas). Thus, experimental realism could heighten utilitarian responses, by activating an approach motivation (i.e., the concern with saving lives), which is otherwise absent in traditional dilemma contexts. Adopting the two-dimensional model of utilitarianism provided convergent evidence: As in previous research (Kahane et al., 2015), when considering traditional sacrificial dilemmas, utilitarian responses depended primarily on the belief that instrumental harm is permissible. In contrast, utilitarian triage decisions were independently linked to both dimensions of utilitarianism: Beliefs about the permissibility of instrumental harm continued to predict utilitarian attitudes toward triage, but so did attitudes of impartial beneficence. 


\section{Implications}

Our study adds to growing concerns that the literature on trolley dilemmas has generated a series of misconceptions about moral cognition in general (Baumann et al. 2012), and utilitarian ethics in particular. First, predominant experimental paradigms may have downplayed the extent to which people endorse utilitarian outcomes in real life (see also Francis et al., 2017; Patil et al., 2014). Relatedly, existing work has associated utilitarian ethics to an antisocial personality (Bartels \& Pizarro, 2011), and yet our present studies demonstrate that utilitarian attitudes can also arise among prosocial individuals - at least when considering moral dilemmas that afford psychological and experimental realism.

On a more promising note, our study reveals that - while the origin and severity of Covid-19 are a matter of profound political division — at least some ethical questions that arise for the allocation of public health resources are not. Liberals and conservatives appear to agree, in large part, on the morality of utilitarian resolutions to dilemmas arising in the context of critical care triage.

\section{Limitations and Future Research}

First, our studies recruited large samples in order to maximize statistical power to observe average-sized effects. As such, even very small individual differences (e.g., the effects of empathy and perspective-taking on moral attitudes) reached the threshold of statistical significance. However, statistical significance does not entail practical significance; so readers should exercise caution and consider both statistical significance and effect size to gauge the relevance of each of our findings.

Second, although we obtained strong evidence that psychological realism exerts an influence on moral judgment, our studies provided limited insight into the mechanism inducing 
this effect. Moderation analyses in Section 5 yielded tentative evidence that prosocial dispositions may explain people's heightened utilitarianism in critical care dilemmas:

Potentially, coronavirus patients elicit attitudes of impartial beneficence to a greater extent than do the nondescript victims of traditional moral dilemmas. However, confirmatory research is needed to establish the credibility of this particular explanation.

Third, given rapid change in the circumstances surrounding the Covid-19 pandemic, we cannot confidently describe any constraints on the generality of our findings. Plausibly, as Covid-19 continues to 'normalize', its psychological salience - the very feature at the core of our findings - might dwindle. If so, a deeper understanding of the present phenomenon may require conceptual adaptations of the present methods to novel contexts.

Fourth, our conclusions are based strictly on online convenience samples of US participants. Research comparing such samples to nationally representative samples underscores that, while demographic differences are pronounced, the results of social science studies generally replicate across sampling methods - with few exceptions (Chandler, Rosenzweig, Moss, Robinson, \& Litman, 2019). Furthermore, studies of utilitarian sacrifice have documented a remarkable degree of universality (Awad et al., 2020). Relatedly, the present tendency toward heightened utilitarianism on triage dilemmas emerged also in a nationally representative sample (Wilkinson et al., 2020).

\section{Conclusion}

Moral psychologists have long debated whether, and under what conditions, people favor utilitarian approaches to the sacrifice of human lives for the greater good. The early stages of the Covid-19 pandemic provided a unique context to explore this issue in circumstances of unprecedented realism and practical relevance: What should frontline ICU professionals do when 
faced with the decision whether to sacrifice one patient and save a larger number of lives?

Despite flagrant political polarization surrounding the origin and severity of Covid-19, liberals and conservatives alike supported utilitarian approaches to the rationing of scarce medical resources during the pandemic. This result could not have easily been predicted by previous research on trolley-type sacrificial dilemmas, perhaps because these unrealistic scenarios fail to muster the same cognitive processes, such as impartial beneficence, that govern utilitarian reasoning about pressing, real-world issues. As a result, our evidence provides grounds for optimism about the multilateral development of public health guidelines to govern triage and allocation of critical care resources. 


\section{References}

Antoniou, R., Romero-Kornblum, H., Young, J. C., You, M., Kramer, J., \& Chiong, W. (ms). No Utilitarians in a Pandemic? Shifts in Moral Reasoning during the COVID-19 Global Health Crisis. https://doi.org/10.31234/osf.io/yjn3u

Aronson, E., Wilson, T. D., \& Brewer, M. B. (1998). Experimentation in social psychology. In G. Lindsay \& E. Aronson (Eds.), The Handbook of Social Psychology (4th edn, Vol. 1, pp. 99-142). Boston, MA: McGraw-Hill.

Arora, C., Savulescu, J., Maslen, H. et al. (2016). The Intensive Care Lifeboat: a survey of lay attitudes to rationing dilemmas in neonatal intensive care. BMC Med Ethics 17, 69 (2016). https://doi.org/10.1186/s12910-016-0152-y

Awad, E., Dsouza, S., Shariff, A., Rahwan, I., \& Bonnefon, J. F. (2020). Universals and variations in moral decisions made in 42 countries by 70,000 participants. Proceedings of the National Academy of Sciences, 117(5), 2332-2337.

Bauman, C. W., McGraw, A. P., Bartels, D. M., \& Warren, C. (2014). Revisiting external validity: Concerns about trolley problems and other sacrificial dilemmas in moral psychology. Social and Personality Psychology Compass, 8(9), 536-554.

Bartels, D. M., \& Pizarro, D. A. (2011). The mismeasure of morals: Antisocial personality traits predict utilitarian responses to moral dilemmas. Cognition, 121(1), 154-161.

Bartels, D. M., Bauman, C. W., Cushman, F. A., Pizarro, D. A., \& McGraw, A. P. (2015). Moral judgment and decision making. The Wiley Blackwell handbook of judgment and decision making, 63, 478-515. 
Bostyn, D. H., Sevenhant, S., \& Roets, A. (2018). Of mice, men, and trolleys: Hypothetical judgment versus real-life behavior in trolley-style moral dilemmas. Psychological science, 29(7), 1084-1093.

Brotherton, R., French, C. C., \& Pickering, A. D. (2013). Measuring belief in conspiracy theories: The generic conspiracist beliefs scale. Frontiers in psychology, 4, 279.

Buckwalter, W., \& Peterson, A. (2020). Public attitudes toward allocating scarce resources in the COVID-19 pandemic. PloS one, 15(11), e0240651.

Campbell, D. T. (1957). Factors relevant to validity of experiments in social settings. Psychological Bulletin, 54, 297-312.

Chandler, J., Rosenzweig, C., Moss, A. J., Robinson, J., \& Litman, L. (2019). Online panels in social science research: Expanding sampling methods beyond Mechanical Turk. Behavior Research Methods, 51(5), 2022-2038.

Christensen, J. F., \& Gomila, A. (2012). Moral dilemmas in cognitive neuroscience of moral decision-making: A principled review. Neuroscience \& Biobehavioral Reviews, 36(4), $1249-1264$.

Cole Wright, J., Cullum, J., \& Schwab, N. (2008). The cognitive and affective dimensions of moral conviction: Implications for attitudinal and behavioral measures of interpersonal tolerance. Personality and Social Psychology Bulletin, 34(11), 1461-1476.

Converse, P. E. (2006). The nature of belief systems in mass publics (1964). Critical review, 18(1-3), 1-74.

Conway, P., \& Gawronski, B. (2013). Deontological and utilitarian inclinations in moral decision making: a process dissociation approach. Journal of personality and social psychology, 104(2), 216. 
Conway, P., Goldstein-Greenwood, J., Polacek, D., \& Greene, J. D. (2018). Sacrificial utilitarian judgments do reflect concern for the greater good: Clarification via process dissociation and the judgments of philosophers. Cognition, 179, 241-265.

Cushman, F., Young, L., \& Hauser, M. (2006). The role of conscious reasoning and intuition in moral judgment: Testing three principles of harm. Psychological science, 17(12), 10821089.

Emanuel, E. J., Persad, G., Upshur, R., Thome, B., Parker, M., Glickman, A., ... \& Phillips, J. P. (2020). Fair allocation of scarce medical resources in the time of Covid-19. New England Journal of Medicine (382), 2049-2055.

Everett, J. A. C. (2013). The 12 item social and economic conservatism scale (SECS). PloS one, 8(12), e82131.

Fox, J., \& Weisberg, S. (2019). An R Companion to Applied Regression, Third edition. Sage: Thousand Oaks, CA.

Francis, K. B., Howard, C., Howard, I. S., Gummerum, M., Ganis, G., Anderson, G., \& Terbeck, S. (2016). Virtual morality: Transitioning from moral judgment to moral action?. PloS one, 11(10), $\mathrm{e} 0164374$.

Francis, K., \& McNabb, C. B. (2021). Moral Decision-Making during COVID-19: Moral judgments, moralisation, and everyday behaviour. https://doi.org/10.31219/osf.io/jvfds.

Francis, K. B., Terbeck, S., Briazu, R. A., Haines, A., Gummerum, M., Ganis, G., \& Howard, I. S. (2017). Simulating moral actions: An investigation of personal force in virtual moral dilemmas. Scientific Reports, 7(1), 1-11.

Foot, P. (1967). The problem of abortion and the doctrine of the double effect in virtues and vices. Oxford Review, 5, 5-15. 
Gleichgerrcht, E., \& Young, L. (2013). Low levels of empathic concern predict utilitarian moral judgment. PloS one, 8(4), e60418.

Graham, J., Haidt, J., \& Nosek, B. A. (2009). Liberals and conservatives rely on different sets of moral foundations. Journal of personality and social psychology, 96(5), 1029.

Greene, J. D., Sommerville, R. B., Nystrom, L. E., Darley, J. M., \& Cohen, J. D. (2001). An fMRI investigation of emotional engagement in moral judgment. Science, 293(5537), 2105-2108.

Greene, J. D. (2007). The secret joke of Kant's soul. In W. Sinnott-Armstrong (Ed.), Moral Psychology, Vol. 3: The Neuroscience of Morality: Emotion, Disease, and Development (pp. 35-117). Cambridge, MA: MIT Press.

Greene, J. D., Cushman, F. A., Stewart, L. E., Lowenberg, K., Nystrom, L. E., \& Cohen, J. D. (2009). Pushing moral buttons: The interaction between personal force and intention in moral judgment. Cognition, 111(3), 364-371.

Hannikainen, I. R., Machery, E., \& Cushman, F. A. (2018). Is utilitarian sacrifice becoming more morally permissible?. Cognition, 170, 95-101.

Hannikainen, I. R., Miller, R. M., \& Cushman, F. A. (2017). Act versus impact: Conservatives and liberals exhibit different structural emphases in moral judgment. Ratio, 30(4), 462493.

Hunter, J. D. (1991). Culture wars: The struggle to define America. New York: Basic Books.

Kahane, G., Everett, J. A. C., Earp, B. D., Farias, M., \& Savulescu, J. (2015). 'Utilitarian’ judgments in sacrificial moral dilemmas do not reflect impartial concern for the greater good. Cognition, 134, 193-209. 
Kahane, G., Everett, J. A., Earp, B. D., Caviola, L., Faber, N. S., Crockett, M. J., \& Savulescu, J. (2018). Beyond sacrificial harm: A two-dimensional model of utilitarian psychology. Psychological Review, 125(2), 131.

Koenigs, M., Young, L., Adolphs, R., Tranel, D., Cushman, F., Hauser, M., \& Damasio, A. (2007). Damage to the prefrontal cortex increases utilitarian moral judgements. Nature, 446(7138), 908-911.

Koenigs, M., Kruepke, M., Zeier, J., \& Newman, J. P. (2012). Utilitarian moral judgment in psychopathy. Social cognitive and affective neuroscience, 7(6), 708-714.

Lenth, R. (2019). emmeans: Estimated Marginal Means, aka Least-Squares Means. R package version 1.4.3.01. https://CRAN.R-project.org/package=emmeans

Luke, D. M., \& Gawronski, B. (2021). Political Ideology and Moral Dilemma Judgments: An Analysis Using the CNI Model. Personality and Social Psychology Bulletin, 0146167220987990.

Mikhail, J. (2007). Universal moral grammar: Theory, evidence, and the future. Trends in Cognitive Sciences, 11, 143-152.

Mikhail, J. (2009). Moral grammar and intuitive jurisprudence: A formal model of unconscious moral and legal knowledge. In D. M. Bartels, C. W. Bauman, L. J. Skitka, \& D. L. Medin (Eds.), Moral Judgment and Decision Making: The Psychology of Learning and Motivation (Vol. 50, pp 27-100). San Diego: Elsevier.

New York Times. (2020). Coronavirus (Covid-19) Data in the United States. https://github.com/nytimes/covid-19-data

Patil, I. (2015). Trait psychopathy and utilitarian moral judgement: The mediating role of action aversion. Journal of Cognitive Psychology, 27(3), 349-366. 
Patil, I., Cogoni, C., Zangrando, N., Chittaro, L., \& Silani, G. (2014). Affective basis of judgment-behavior discrepancy in virtual experiences of moral dilemmas. Social neuroscience, 9(1), 94-107.

Patil, I., \& Silani, G. (2014). Reduced empathic concern leads to utilitarian moral judgments in trait alexithymia. Frontiers in psychology, 5, 501.

Pew Research Center (June 2020a), “Three Months In, Many Americans See Exaggeration, Conspiracy Theories and Partisanship in COVID- 19 News."

Pew Research Center (June 2020b), "Republicans, Democrats Move Even Further Apart in Coronavirus Concerns".

Pew Research Center (July 2020c), "Republicans remain far less likely than Democrats to view COVID-19 as a major threat to public health".

Reeskens, T., Roosma, F., \& Wanders, E. (2021). The perceived deservingness of COVID-19 healthcare in the Netherlands: a conjoint experiment on priority access to intensive care and vaccination. BMC public health, 21(1), 1-8.

Romero-Rivas, C., \& Rodriguez-Cuadrado, S. (2021). The Psychological Impact of the COVID19 Pandemic Affected Decision-Making Processes. The Spanish journal of psychology, 24 .

Rozin, P., Lowery, L., Imada, S., \& Haidt, J. (1999). The CAD triad hypothesis: a mapping between three moral emotions (contempt, anger, disgust) and three moral codes (community, autonomy, divinity). Journal of personality and social psychology, 76(4), 574. 
Skitka, L. J., Bauman, C. W., \& Sargis, E. G. (2005). Moral conviction: Another contributor to attitude strength or something more?. Journal of personality and social psychology, $88(6), 895$.

Tenbrunsel, A. E., \& Messick, D. M. (1999). Sanctioning systems, decision frames, and cooperation. Administrative Science Quarterly, 44(4), 684-707.

The Atlantic. (2020). The Extraordinary Decisions Facing Italian Doctors. https://www.theatlantic.com/ideas/archive/2020/03/who-gets-hospital-bed/607807/

Thomson, J. J. (1976). Killing, letting die, and the trolley problem. The Monist, 59, 204-217.

Thomson, J. J. (1985). The trolley problem. Yale Law Journal, 94, 1395-1415.

Wilkinson, D., Zohny, H., Kappes, A., Sinnott-Armstrong, W., \& Savulescu, J. (2020). Which factors should be included in triage? An online survey of the attitudes of the UK general public to pandemic triage dilemmas. BMJ Open, 10:e045593. doi: 10.1136/bmjopen2020-045593.

Wilkinson, W. (2019). The Density Divide: Urbanization, Polarization, and Populist Backlash. Niskanen Center Research Paper. 